\title{
Possible Effect of Perampanel on Epilepsia Partialis Continua after Generalized Tonic-Clonic Status Epilepticus
}

\author{
Tae-Won Yang, $\mathrm{MD}, \mathrm{PhD}^{1}$, Do-Hyung Kim, $\mathrm{MD}, \mathrm{PhD}^{2}$, Young-Soo Kim, $\mathrm{MD}, \mathrm{PhD}^{3}$ \\ ${ }^{1}$ Department of Neurology, Gyeongsang National University Changwon Hospital, Changwon, Korea \\ ${ }^{2}$ Department of Neurology, Samsung Changwon Hospital, Sungkyunkwan University School of Medicine, Changwon, Korea \\ ${ }^{3}$ Department of Neurology, Gyeongsang National University Hospital, Jinju, Korea
}

Received: August 24, 2021

Revised: September 18, 2021

Accepted: September 18, 2021

Corresponding author:

Young-Soo Kim, MD, PhD

Department of Neurology,

Gyeongsang National University

Hospital, 79 Gangnam-ro, Jinju 52727,

Korea

Tel: $+82-55-750-8077$

Fax: +82-55-750-1709

E-mail: youngsookim0127@gmail.com
Epilepsia partialis continua (EPC), defined as a syndrome of continuous focal motor seizures, is a rare form of status epilepticus. EPC is a difficult-to-treat condition that tends to be refractory. Perampanel (PER) is the most recently approved antiepileptic drug for focal and generalized epilepsy and has a distinct and selective mode of action on alpha-amino-3-hydroxy-5-methyl-4-isoxazolepropionic acid receptors. There are also anecdotal reports on its use in status epilepticus. Herein, we present a case where PER was the last antiepileptic drug introduced for the treatment of EPC before its termination 48 hours later. PER might be a safe choice that can be considered as an additional option for patients with EPC.

Keywords: Perampanel; Epilepsia partialis continua; Status epilepticus

\section{Introduction}

Status epilepticus (SE) is a serious neurological disease characterized by persistent seizures that do not stop on their own. It has a relatively high incidence rate ${ }^{1}$ and a mortality rate of more than $20 \%{ }^{2,3}$ The underlying pathophysiological changes in persistent seizures are known to be an imbalance in the levels of the inhibitory neurotransmitter gamma-aminobutyric acid (GABA) and the excitatory neurotransmitter glutamate. ${ }^{4,5}$ If seizures persist despite the use of second-line antiepileptic drugs (AEDs), refractory SE (RSE) is diagnosed. Intensive treatment and anesthetic drug use can be considered depending on the type of seizures. ${ }^{6,7}$ As seizures persist, postsynaptic GABA receptors can internalize into the cytoplasm and alter the homeostasis of chloride, diminishing the effect of GABAergic drugs. ${ }^{8}$ At this point in time, glutamate as an excitatory neurotransmitter plays an important role in maintaining seizures through alpha amino-3-hydroxy-5-meth- yl-4- isoxazolepropionic acid (AMPA) receptors. Perampanel (PER) is a new anticonvulsant drug that acts as a noncompetitive antagonist of AMPA receptors. The effect of PER on various types of SE has been reported in several cases. Previously, we have confirmed that PER exerts a seizure-controlling effect in SE without causing any harmful reactions. ${ }^{9-12}$ Here, we present a case wherein recovery was achieved after the introduction of PER in a patient with epilepsia partialis continua (EPC) after generalized tonic-clonic SE.

\section{Case}

A 52-year-old man presented to the emergency room (ER) with repeated seizures. At the age of 13 years, he was diagnosed with epilepsy. He was prescribed valproic acid (600 mg), carbamazepine (600 mg), phenytoin (300 mg), and diazepam (6 mg) at another clinic. His drug compliance was good, but he had inter-

This is an Open Access article distributed under the terms of the Creative Commons Attribution Non-Commercial License (http://creativecommons.org/licenses/by-nc/4.0/) which permits unrestricted non-commercial use, distribution, and reproduction in any medium, provided the original work is properly cited.

Copyright @ 2021 Korean Clinical Epilepsy Research Society 
mittent seizures. His caregiver found that he had lost consciousness on the day of his visit. On the way to the ER, he experienced generalized tonic-clonic seizures several times. Upon arrival to the ER, lorazepam (7 mg) was administered intravenously. The initial plasma level of carbamazepine was $6.7 \mu \mathrm{g} / \mathrm{mL}$, that of valproic acid was $65.99 \mu \mathrm{g} / \mathrm{mL}$, and that of phenytoin was 11.84 $\mu \mathrm{g} / \mathrm{mL}$. His consciousness did not recover from stupor; however, there were no seizures with motor symptoms. Brain magnetic resonance imaging performed in the ER showed no acute or new lesions. There were no abnormal lab findings that were thought to be the cause of epilepsy. On the next day, electroencephalography (EEG) showed sustained and periodic epileptiform discharges in the left temporal lobe (Fig. 1). After EEG, $40 \mathrm{mg} / \mathrm{kg}$ of levetiracetam was injected as a loading dose and 2,000 mg/day was chosen as a maintenance dose. After the loading dose of lorazepam and levetiracetam, there were no seizures and EEG showed improvement (Fig. 2). On the third day of treatment, his consciousness gradually recovered and the patient spontaneously opened his eyes. On the fourth day, he improved to the level of speaking single word. Dietary intake became possible on the seventh day of treatment. On the eighth day of treatment, seizures reappeared despite the injections of levetiracetam, valproic acid, and fosphenytoin with maintained doses. On the next day, EEG findings (Fig. 3) showed periodic epileptiform discharges, similar to the initial EEG. Repeated seizures occurred dozens of times a day, with the patient's eyeballs and head turning right. At that time, his consciousness was drowsy, but simple communication was possible. This condition was recognized as EPC. Considering the deteriorating EEG findings, a decision was made to add a load-capacity treatment of an AED that could be used orally rather than using general anesthesia with intensive treatment. We decided to use PER in light of the mechanism of action of this drug. First, $6 \mathrm{mg}$ of PER was loaded and the other AEDs in use remained the same. The dose was increased by $2 \mathrm{mg}$ per day while observing the patient's progress. After a day of using PER, a gradual decrease in the number of seizures was noted, and symptoms disappeared completely on the third day of treatment. There were no adverse effects of the drug. On the sixth day of treatment, the EEG findings normalized (Fig. 4) and there were no episodes of seizures. EEG findings were also normal at the time of the patient's discharge from the hospital.

\section{Conclusion}

PER is a first-in-class selective AMPA receptor antagonist that has been licensed and marketed as an AED indicated for patients with partial-onset and primary generalized tonic-clonic seizures. $^{13}$ Animal studies confirming the pathophysiology of SE have shown that the delivery of glutamate associated with AMPA receptors is enhanced in sustained states of established SE. This

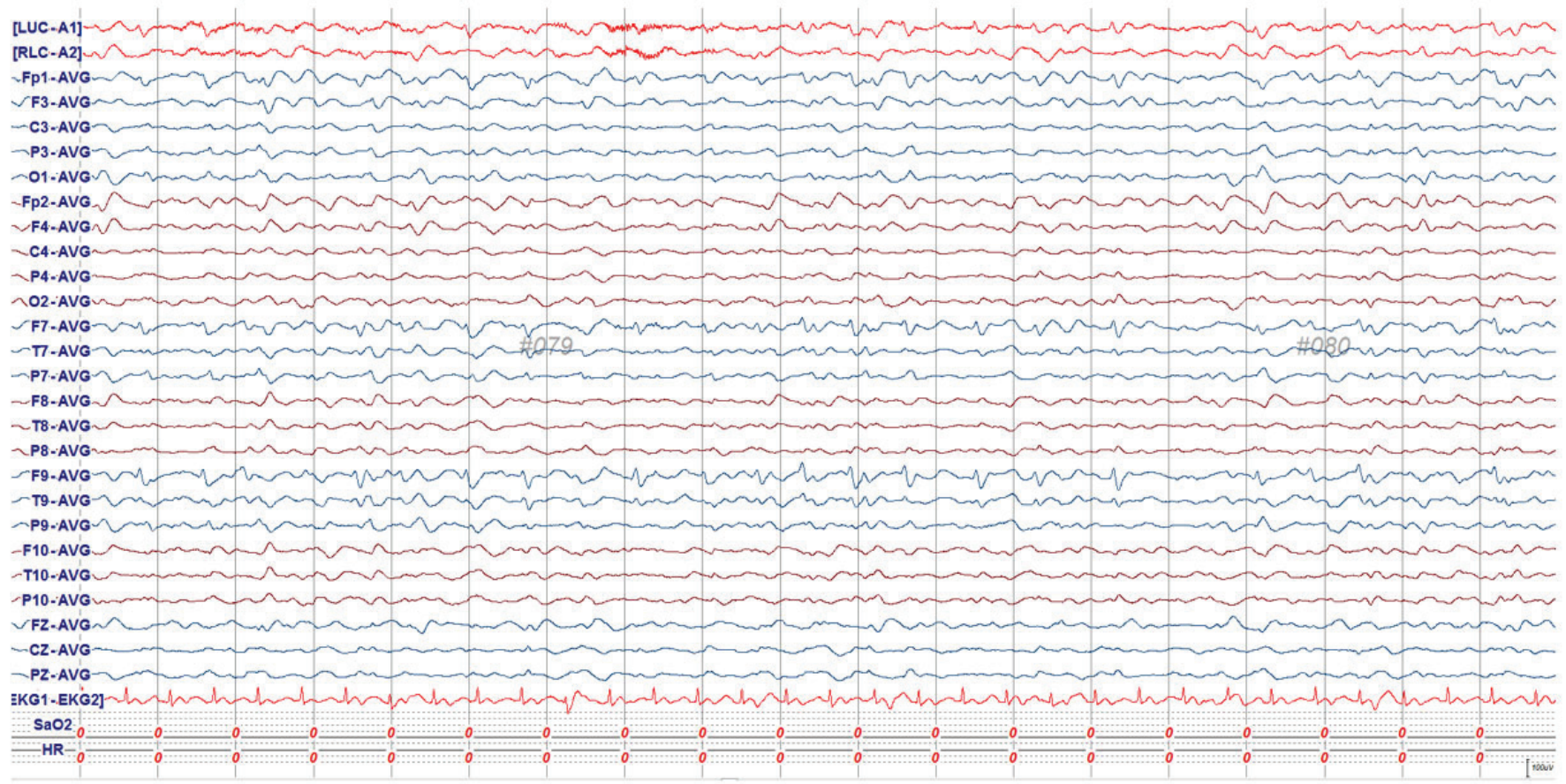

Fig. 1. Initial electroencephalography in the emergency room showed continuous quasiperiodic sharp and waves on the left temporofrontal area. 


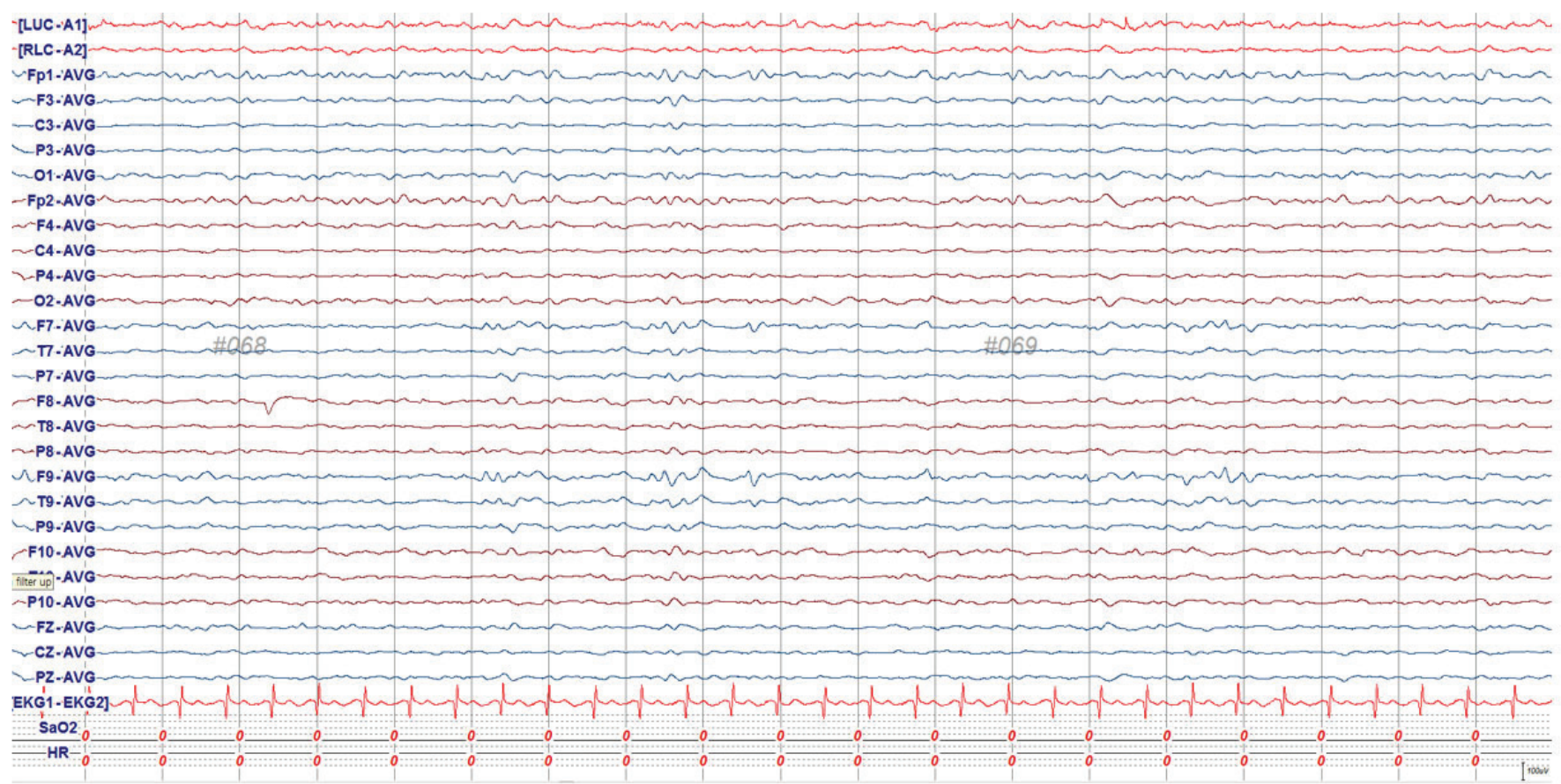

Fig. 2. Decreased quasiperiodic discharges after infusion of lorazepam and levetiracetam loading dose.

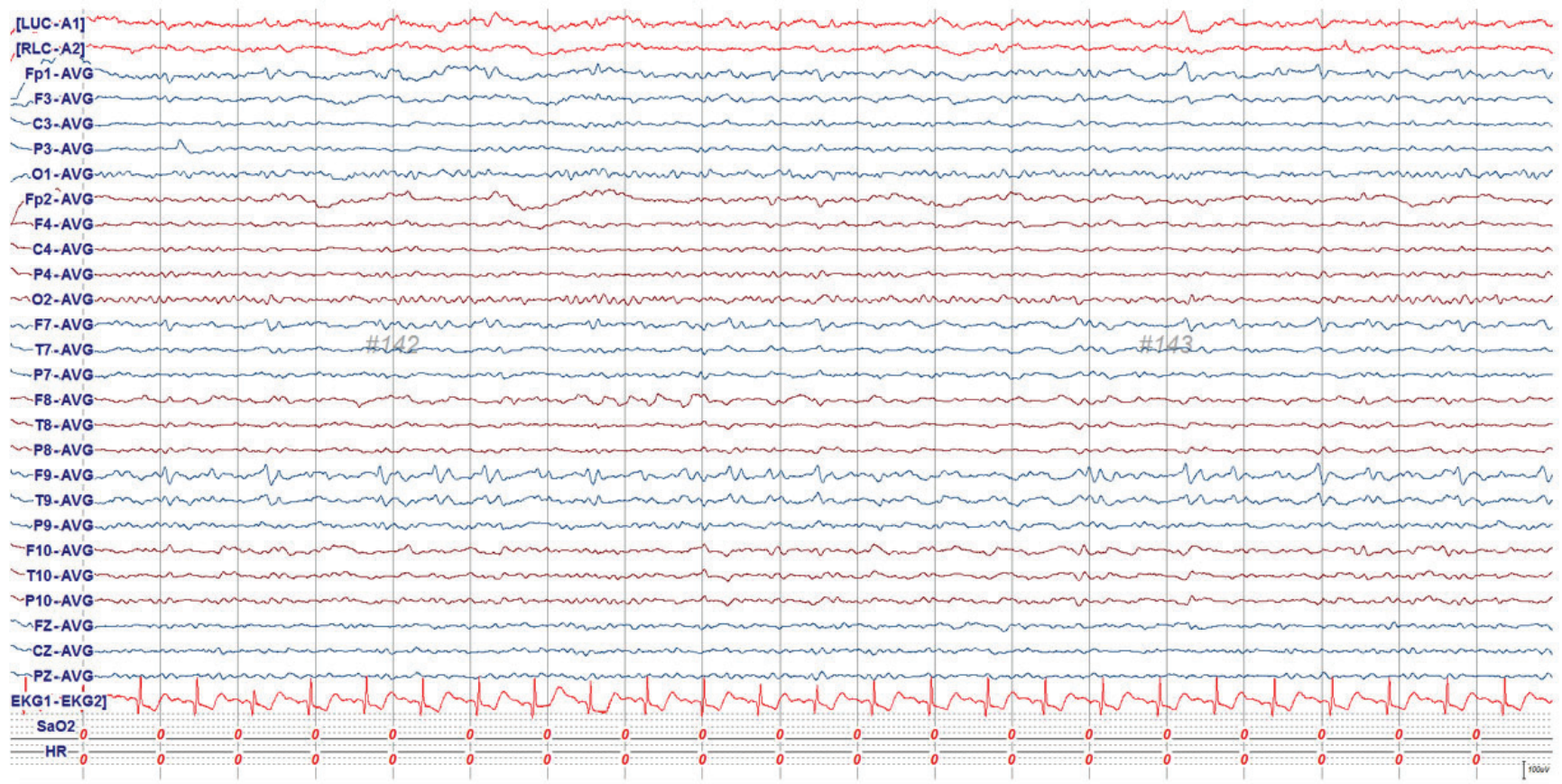

Fig. 3. Electroencephalography (EEG)showed aggravation of same as initial EEG patterns.

finding provides an explanation for why the therapeutic effect of GABAergic drugs is reduced at this period. ${ }^{14}$ An experimental study has confirmed the effect of PER on established SE with high resistance to GABAergic drugs. PER has also been proven to have an effect on the termination of diazepam-resistant SE in a lithium-pilocarpine rat model. ${ }^{15}$ In addition, synergistic effects were observed when PER was co-administered with diazepam in the same model. ${ }^{16}$

Based on the results of these animal studies, the use of PER has been attempted in SE of various causes and types, and therapeu- 


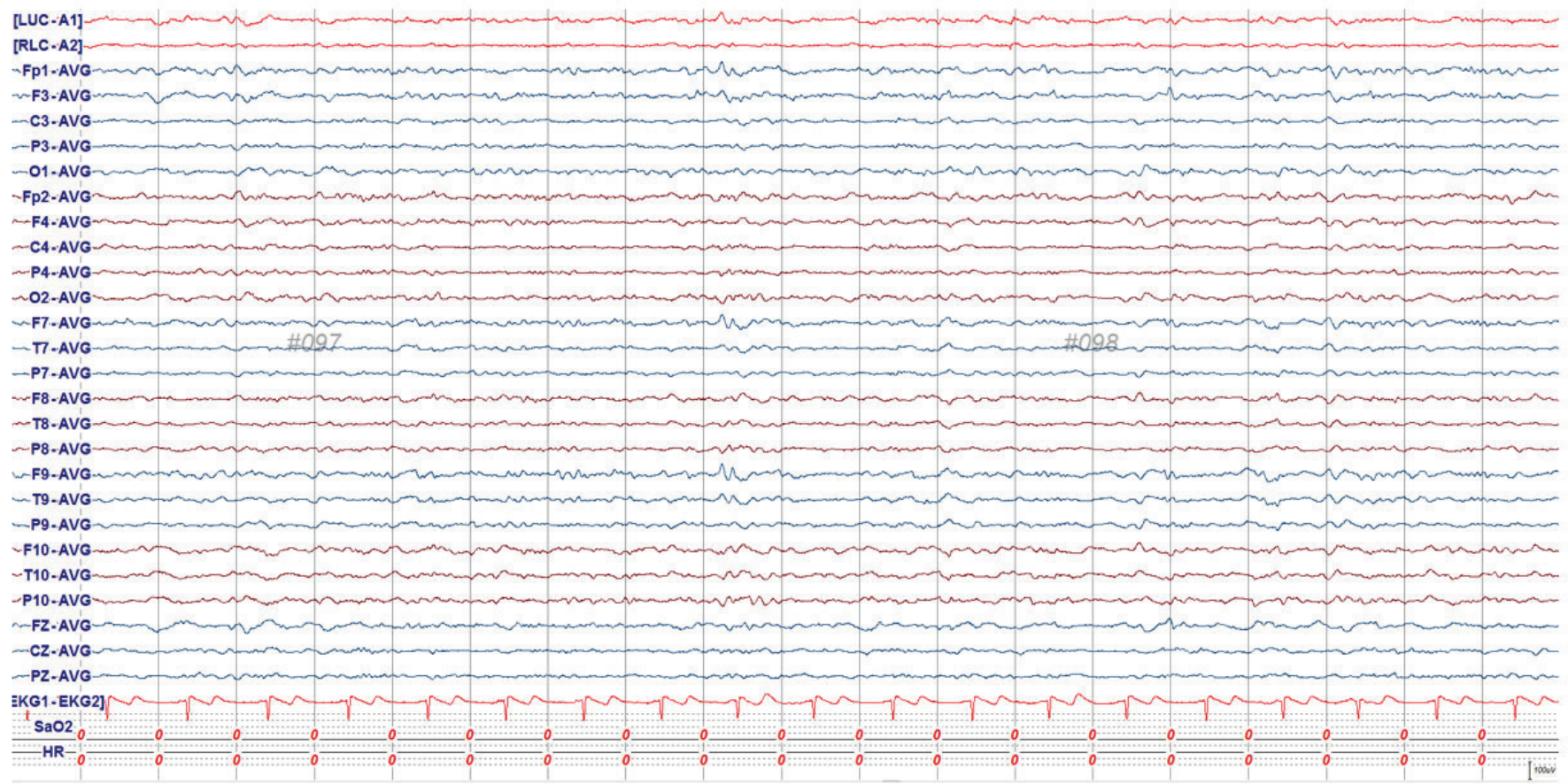

Fig. 4. Improved electroencephalography state after taking perampanel loading dose.

tic responses have been reported. ${ }^{9-12}$ In 2013, Rösche et al. ${ }^{9}$ reported the case of an 81-year-old woman who had been taking levetiracetam and valproic acid for poststroke epilepsy and received PER as an add-on treatment for focal SE. Rohracher et al. $^{11}$ reported that 12 patients in the neurological intensive care unit received PER for RSE and super-RSE between September 2012 and November 2014. The initial dose was $4 \mathrm{mg}$. There was one case of clinical improvement within 24 hours after PER administration and one case of improvement within 48 hours. The response rate was not high due to the difficulty of anticipating clinical improvement. However, PER was evaluated as a relatively safe drug because no harmful reaction was observed. ${ }^{10}$ A case series also described the application of PER in nine patients with RSE who had nonconvulsive SE (NCSE). Most of these patients used $6 \mathrm{mg}$ of PER as the initial loading dose. It was found to be effective except in two patients. ${ }^{11}$ In 2016, the same authors published a report of successful treatment of focal SE in patients with Rasmussen encephalitis using PER. ${ }^{9}$ In this case, PER was safe and had a long-lasting effect. ${ }^{12}$

Termination of SE is clinically defined as the end of seizure symptoms accompanied by motor activity in EPC and as recovery to basal consciousness or the resolution of previously documented EEG abnormalities in NCSE. Thus, different criteria exist for judging termination according to the form of SE. Since patients with RSE are treated with many AEDs at the same time, specific criteria are needed to decide which drug has terminated the SE, but each study has used slightly different criteria for this purpose.

In a study where topiramate was administered to patients with RSE, a successful response was defined as a clinical and EEG improvement obtained within 96 hours after topiramate administration without any changes in other drugs used. A possible response was defined as improvement in cases where there were changes in other drugs besides topiramate during the same period. ${ }^{17}$

In the case described herein, the patient presented with SE accompanied by generalized tonic-clonic seizures, and the seizure symptoms disappeared after the lorazepam loading dose. Subsequently, the seizures became worse in the stage of recovering consciousness. There arose repeated motor seizures, which were diagnosed as EPC. At that point, we decided to use PER. Since EPC terminated within 48 hours after PER administration without changes in the dosage of other drugs, it would be appropriate to consider PER as the specific drug responsible for terminating EPC. Thus, in patients receiving AEDs for EPC, PER may be considered as an additional selective drug with a safe profile.

\section{Notes}

\section{Conflicts of interest}

No potential conflicts of interest relevant to this article were reported. 


\section{Acknowledgements}

None.

\section{References}

1. Neligan A, Shorvon SD. Frequency and prognosis of convulsive status epilepticus of different causes: a systematic review. Arch Neurol 2010;67:931-940.

2. Logroscino G, Hesdorffer DC, Cascino G, Annegers JF, Hauser WA. Short-term mortality after a first episode of status epilepticus. Epilepsia 1997;38:1344-1349.

3. Logroscino G, Hesdorffer DC, Cascino G, et al. Mortality after a first episode of status epilepticus in the United States and Europe. Epilepsia 2005;46 Suppl 11:46-48.

4. Chen JW, Wasterlain CG. Status epilepticus: pathophysiology and management in adults. Lancet Neurol 2006;5:246-256.

5. Naylor DE, Liu H, Wasterlain CG. Trafficking of GABA(A) receptors, loss of inhibition, and a mechanism for pharmacoresistance in status epilepticus. J Neurosci 2005;25:7724-7733.

6. Meierkord H, Holtkamp M. Non-convulsive status epilepticus in adults: clinical forms and treatment. Lancet Neurol 2007; 6:329-339.

7. Meierkord H, Boon P, Engelsen B, et al. EFNS guideline on the management of status epilepticus in adults. Eur J Neurol 2010; 17:348-355.

8. Deeb TZ, Maguire J, Moss SJ. Possible alterations in GABAA receptor signaling that underlie benzodiazepine-resistant seizures.
Epilepsia 2012;53 Supp1 9:79-88.

9. Rösche J, Kampf C, Benecke R. Possible effect of perampanel on focal status epilepticus after generalized tonic-clonic status epilepticus. Acta Neurol Belg 2014;114:243-244.

10. Redecker J, Wittstock M, Benecke R, Rösche J. Efficacy of perampanel in refractory nonconvulsive status epilepticus and simple partial status epilepticus. Epilepsy Behav 2015;45:176-179.

11. Rohracher A, Höfler J, Kalss G, et al. Perampanel in patients with refractory and super-refractory status epilepticus in a neurological intensive care unit. Epilepsy Behav 2015;49:354-358.

12. Göde K, Grossmann A, Roesche J. Successful treatment of epilepsia partialis continua due to rassmussen encephalitis with perampanel. J Epileptol 2016;24:31-34.

13. Franco V, Crema F, Iudice A, Zaccara G, Grillo E. Novel treatment options for epilepsy: focus on perampanel. Pharmacol Res 2013;70:35-40.

14. Rajasekaran K, Joshi S, Kozhemyakin M, et al. Receptor trafficking hypothesis revisited: plasticity of AMPA receptors during established status epilepticus. Epilepsia 2013;54 Suppl 6:14-16.

15. Ido K, Hanada T. Perampanel terminates diazepam-resistant status epilepticus in a lithium-pilocarpine rat model. Epilepsia 2013;54(Suppl 6):109, abstract P11.

16. Hanada T, Ido K. Synergistic effects of perampanel combined with diazepam in the lithium-pilocarpine rat model of status epilepticus. Epilepsia 2013;54(Suppl 6):108-109, abstract P10.

17. Stojanova V, Rossetti AO. Oral topiramate as an add-on treatment for refractory status epilepticus. Acta Neurol Scand 2012; 125:e7-e11. 
